\title{
RESENHA
}

\section{MARXISMO E VIDEOGAMES PARA ALÉM DA IMAGEM}

\author{
MARXISMO Y VIDEOJUEGOS MÁS ALLÁ DE LA IMAGEN
}

MARXISM AND VIDEOGAMES BEYOND THE IMAGE

\section{DOI: 10.22481/RBBA.V10I02.9703}

Daniel Santos Mota

Secretaria de Educação do Estado da Bahia, Bahia, Brasil

ORCID: https://orcid.org/0000-0002-6002-1909

Lattes: http://lattes.cnpq.br/3659559990231778

Endereço eletrônico: danielsff@ gmail.com

Resenha de WOODCOCK, Jamie. Marx no fliperama: videogames e luta de classes. São Paulo, SP: Autonomia Literária, 2020, 326 págs.

\begin{abstract}
RESUMO
A presente resenha trata do livro "Marx no fliperama: Videogames e luta de classes", que faz uma análise temática do referido livro. Na obra, o autor faz uma investigação da moderna indústria dos jogos eletrônicos sob a perspectiva do Materialismo Histórico, buscando compreender os videogames em sua totalidade, desde a história do jogar, passando pela produção, comércio, relações de produção e organização da classe trabalhadora envolvida na produção destes jogos. Esta é uma obra que demonstra que os videogames, assim como toda a sociedade, são campo de
\end{abstract}


disputa entre as classes sociais, e neste momento está quase completamente controlada pela burguesia. Para o autor, esse quadro deve ser alterado.

PALAVRAS-CHAVE: Marxismo. Materialismo Histórico. Vídeogames. Luta de classes.

\section{RESUMEN}

Esta revisión trata sobre el libro "Marx en el flipper: videojuegos y lucha de clases", que hace un análisis temático del libro referido. En la obra, el autor investiga la industria moderna de los juegos electrónicos desde la perspectiva del Materialismo Histórico, buscando entender los videojuegos en su totalidad, desde la historia de juego, pasando por la producción, el comercio, las relaciones de producción y la organización de la clase trabajadora involucrada en la producción de estos juegos. Este es un trabajo que demuestra que los videojuegos, así como la sociedad en su conjunto, son campo de disputa entre clases sociales, y en este momento está casi completamente controlado por la burguesia. Para el autor, este cuadro debe cambiarse.

PALABRAS CLAVE: Marxismo. Materialismo historico. Videojuegos. Lucha de clases.

\section{ABSTRACT}

This review deals with the book "Marx in the arcade: Videogames and class struggle", which makes a thematic analysis of the referred book. In the work, the author investigates the modern electronic games industry from the perspective of Historical Materialism, seeking to understand video games in their entirety, from the history of playing, through production, trade, production relations and the organization of the working class involved in the production of these games. This is a work that demonstrates that videogames, as well as all of the society, are a field of dispute between social classes, and at the moment it is almost completely controlled by the bourgeoisie. For the author, this situation should be changed.

Keywords: Marxism. Historical Materialism. Videogames. Class Struggle. 
Durante muito tempo, os videogames foram considerados uma brincadeira de crianças e mesmo os seus desenvolvedores, trabalhadores com alta qualificação, eram vistos como pessoas que tinham um trabalho leve, divertido, quase como se trabalhassem brincando. O que o britânico Jamie Woodcock, um sociólogo do trabalho, revela em seu livro, é que a indústria de produção de jogos e seu gigantesco mercado são muito mais do que o senso comum pode apreender.

$\mathrm{O}$ autor inicia sua pesquisa pelo seu interesse pessoal nos jogos, tendo sido um "gamer"i por toda a sua vida, como demonstra desde a introdução, tendo jogado todos os grandes títulos produzidos, pelo menos desde o fim da década de 1980. Somado a esse interesse, também está o seu envolvimento com a teoria marxista e com o movimento socialista em seu país, sendo ele integrante do conselho editorial das revistas Notes from below e Historical Materialism, publicações que reivindicam a tradição marxista e socialista.

Publicado originalmente em 2019 com o título "Marx on the arcade consoles", Marx no fliperama foi publicado no Brasil no ano de 2020 pela editora Autonomia Literária. O livro está dividido em duas partes centrais, agrupando temas comuns, além da introdução e conclusão, que também trazem questões relevantes para entender o autor, o livro e a indústria/mercado dos jogos. Descrita a organização formal do livro, essa resenha não seguirá o padrão de discutir a obra capítulo a capítulo, pois a abordará a partir dos temas centrais do texto.

Woodcock, revela o livro, é um assíduo jogador de videogames desde a infância nos anos 1980 e a obra traz vários detalhes do seu desenvolvimento como gamer, década após década, apontando os jogos que mais marcaram o autor. Uma experiência que parece ter sido determinante para que a pesquisa fosse realizada, foi a aparição de Karl Marx no jogo Assassin's Creed: Syndicate como um $N P C^{i i}$, tendo sido representado de forma precisa e inspirou o autor para que ele unisse seus dois principais interesses em um livro, o marxismo e os videogames.

O livro faz excelente reconstituição histórica da indústria dos jogos eletrônicos, relacionando os primeiros games à Guerra Fria e ao complexo industrial-militar, como jogos de guerra, tentativas de simulação tática num possível conflito armado entre os EUA e a extinta URSS. A primeira fase histórica da produção de jogos era marcada por uma cultura "hacker", quando havia grande liberdade dos desenvolvedores, além do compartilhamento de informações e participação de uma grande comunidade. Nesse período, que vai da década de 1960 até o início dos anos 1980, os desenvolvedores tinham uma relevante autonomia, fosse no setor militar ou no privado, especialmente com a Atari, que, para atrair novos desenvolvedores, prometia que os trabalhadores teriam o "jogar como forma de trabalhar".

Revista RBBA Revista Binacional Brasil Argentina Vol. 10, num. 2, dez/2021, p. 406-413 
Ainda nesta temática, Woodcock traz o leitor até a década de 2010, passeando detalhadamente por cada lançamento de console além dos jogos mais marcantes de cada geração, denotando o vultoso crescimento que a indústria obteve nas últimas décadas, o que levou a uma mudança na relação dos desenvolvedores com os estúdios, das editoras com as lojas e dos jogadores com videogames, que passaram a ser, segundo palavras do autor, um "fenômeno de massas nos dias atuais" (WOODCOCK, 2020 p. 70).

O livro analisa profundamente o processo de produção, atentando para o fato óbvio, mas muitas vezes esquecido, de que as mercadorias não surgem nas prateleiras como obra de mágica, sendo fruto de trabalho de uma imensa cadeia de trabalhadores, cadeia esta que vai desde a extração dos minerais necessários para a produção do console, passando pelos trabalhadores do transporte e do comércio, pelos desenvolvedores de jogos. Ora escrevendo códigos, ora compondo músicas, concebendo todos os elementos artísticos que um jogo necessita para existir e sem se esquecer daqueles que atuam silenciosamente nos estúdios, garantindo a limpeza e o abastecimento dos escritórios onde os jogos são produzidos. A obra traduz uma análise inspirada no melhor espírito do materialismo histórico, demonstrando como a essência das coisas vai além das suas aparências, conforme admoestava o próprio Marx (2017, p. 880) "toda ciência seria supérflua se a forma de manifestação e a essência das coisas coincidissem imediatamente".

Woodcock também debate o tamanho da indústria contemporânea de games a partir dos dados do ano de 2018 trazidos por uma fonte que condensa as informações das empresas, e deixa claro que a confiabilidade destes dados é apenas relativa, e advém do fato de que a própria indústria se vale deles para organizar a produção. Entrando nos números, propriamente ditos, a receita total para o referido ano foi de 108,4 bilhões de dólares, englobando jogos para celulares, computadores, consoles e também todo o espetáculo que envolve a transmissão de jogadores comuns, celebridades ou de campeonatos dos chamados "e-sports". A indústria dos jogos eletrônicos conta com o produto de entretenimento de maior sucesso de todos os tempos, o jogo Grand Theft Auto V (Ou GTA V), que já vendeu mais de "90 milhões de unidades ao redor do mundo e gerando mais de 6 bilhões de dólares em receita global." (WOODCOCK, 2020 p. 78).

Diante dessas informações, o autor aponta para uma mudança na forma como os jogos têm sido encarados pela sociedade nas últimas décadas, rememorando as polêmicas sobre a violência dos jogos, presentes especialmente na década de 1990 e início dos anos 2000, quando políticos, jornais impressos e redes de televisão levaram a cabo extensa campanha de difamação contra os jogos de videogame. Para tanto, resgata falas de políticos britânicos proeminentes, como o primeiro ministro

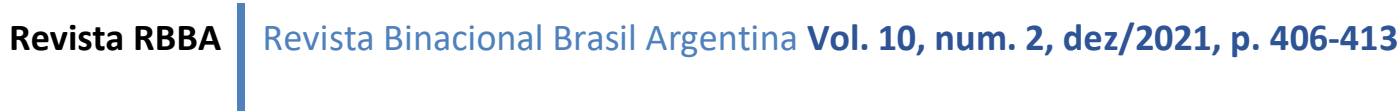


Boris Johnson, que em 2006 afirmou em artigo (que trazia o título "jogos de computador apodrecem o cérebro") que os jogadores de videogames “[...] tornam-se lagartos pestanejantes, sem movimento, absorvidos, apenas os espasmos de suas mãos mostrando que ainda estão conscientes" (WOODCOCK, 2020 p. 79), sobre os jogos ele também afirmava que: "Essas maquinas não os ensinam coisa alguma. Elas não estimulam nenhum raciocínio, descoberta ou trabalho de memória alguns deles podem habilmente fingir-se como educacionais...” (WOODCOCK, 2020 p. 79).

A seguir, Woodcock aponta como essa visão negativa se dissipou tão logo a produção e o mercado de jogos se consolidou como importante setor econômico no Reino Unido, tendo grandes companhias localizadas no país, inclusive a Rockstar North, responsável pelo supracitado GTA V. Dez anos depois o próprio Johnson exaltaria a importância econômica, social e educativa dos jogos como demonstra o discurso apresentado na página 80 da obra. Isso tudo está relacionado como os jogos tem sido importante setor econômico diante de um quadro de desindustrialização dos países europeus e dos próprios EUA na última década, de modo que a indústria dos videogames tem sido um importante elemento de reprodução de capital nesse contexto.

O livro também faz uma excelente discussão acerca da lucratividade dos jogos diante do fato de que são mercadorias produzidas por trabalhadores assalariados produtores de valor, e, obviamente, de mais-valor, fonte de lucro de toda produção capitalista, e os jogos, segundo ele, não se limitariam apenas ao componente econômico, sendo, ainda hoje, importantes veículos ideológicos para o complexo industrial-militar como propaganda de armas e do militarismo.

$\mathrm{Na}$ investigação das condições de trabalho dos trabalhadores da indústria, o autor revela ter tido grandes dificuldades, pois ao contrário de Marx, que durante os estudos para a escrita de $O$ Capital, teve acesso aos relatórios produzidos pelos inspetores de fábricas, os contratos de trabalho dos desenvolvedores e outros agentes envolvidos na produção estão submetidos a rigorosos acordos de confidencialidade, que silenciam e isolam os trabalhadores.

Apesar dessas dificuldades inerentes à pesquisa dessa indústria, o livro esclarece muitos dos problemas pelos quais passam os desenvolvedores dos jogos, seja através de questionários nos quais há anonimato, seja através de casos onde terríveis condições de trabalho são expostas através de denúncias públicas, como a "carta da esposa de um desenvolvedor da EA" (WOODCOCK, 2020 pp. 142-144).

Neste documento de 2004, a referida esposa, revela as condições as quais o seu marido estava submetido, desde a sua admissão na empresa, quando, na entrevista, foi perguntado se estava disposto a trabalhar por várias horas, sem que o significado dessas "várias horas" fosse esclarecido. A realidade

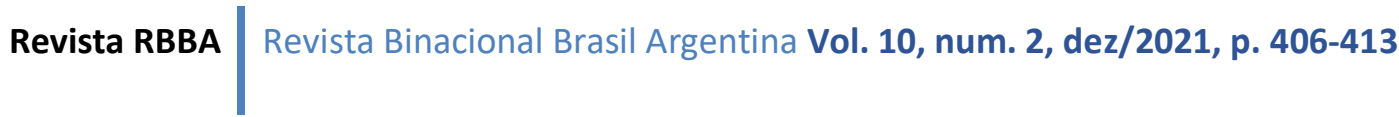


só veio à tona quando os "momentos críticos" do desenvolvimento se iniciaram e os desenvolvedores do estúdio passaram a trabalhar até 85 horas por semana sem o recebimento de horas extras, sem direito a banco de horas ou licença por doença ou férias.

Tratados inicialmente como exceções no processo de desenvolvimento dos jogos, os "momentos críticos" se tornaram uma norma no cronograma da produção, que é planejado levando em consideração que o grupo de trabalhadores precisará passar muito mais tempo no estúdio do que o contratado. Um dos casos mais recentes e que mais chamaram a atenção foi a do jogo Cyberpunk 2077, do estúdio polonês CD Project Red. Foi revelado que os desenvolvedores passaram meses a fio submetidos a jornadas de mais de 10 horas diárias, as vezes durante todos os dias da semana ${ }^{\mathrm{iii}}$, apesar do estúdio ter prometido em momentos anteriores que os trabalhadores não seriam submetidos a períodos de crunch $^{i v}$.

Outra situação nos ajuda a entender como a superexploração do tempo nessa indústria tem papel diretamente relacionado à lucratividade dos jogos: o caso do adiamento de Animal Crossing: New Horizons da Nintendo. Inicialmente, o jogo, de grande sucesso mercadológico, seria lançado no ano de 2019, mas acabou sendo adiado para março do ano seguinte. Em relação a isso, a empresa alegou não querer submeter os desenvolvedores a longos períodos de trabalho e que preferia que eles tivessem melhor equilíbrio entre o trabalho e a vidav ${ }^{\mathrm{v}}$. O resultado dessa medida foi uma queda vertiginosa nas ações da empresa, que perdeu 1 bilhão de dólares em valor de mercado ${ }^{\text {vi }}$ em um único dia após o anuncio.

Outro fator de preocupação dos trabalhadores da indústria dos jogos, aponta o livro, é o assédio moral e sexual dentro dos estúdios, principalmente de mulheres que são minoria nos estúdios que também vivenciam uma diferença salarial incômoda. $\mathrm{O}$ caso mais exemplar que revela como estes fatos são comuns nos estúdios e editoras, foi o da Activision Blizzard, que veio à tona em julho de 2021, quando, após dois anos de investigação, o Tribunal Superior de Los Angeles abriu um processo contra a empresa por assédio moral, sexual e sexismo ${ }^{\text {vii }}$.

Esse caso gerou uma onda de protestos de jogadores e desenvolvedores em vários países, levando com que centenas de milhares de jogadores abandonassem o jogo World of Warcraft, fazendo com que a empresa perdesse dinheiro com as mensalidades que eram pagas pelos jogadores e revelou aquilo que o livro já apontava, essas histórias são comuns na indústria.

Além de todas essas questões apresentadas, o livro também se dedica a uma análise mais detida dos elementos ideológicos presentes em alguns jogos específicos, como os jogos de tiro (conhecidos também como FPS $S^{\text {viii }}$ ), de estratégia e os RPGs. O autor critica o fato de que muitos dos 
jogos FPS reproduzem uma ideologia nacionalista e militarista, influenciando os jogadores pensarem a realidade a partir delas. Sobre os jogos de estratégia, a análise de Woodcock ressalta como esses jogos propagam uma versão linear da história, onde todos as sociedades devem seguir um único fluxo histórico, indo da antiguidade rumo à sociedade capitalista, além do fato de que esses jogos ignoram também o elemento da luta de classes, mas essas questões se tornam releváveis diante da imensa dificuldade de se programar a complexidade das sociedades humanas.

A editora deveria atentar para dois equívocos na tradução/adaptação do texto, na página 54 lê-se "Colocavam-se as instruções selecionando um clube de golfe específico", certamente o texto original traz a palavra golf club, que significa, na realidade, "taco de golfe", não "clube de golfe", como a tradução aponta. Na página 67 é possível ver uma adaptação equivocada do texto para o português, quando o autor não traduziu a palavra "handheld", que em português se utiliza a palavra "portátil" para se referir àqueles consoles "de mão" ou que não precisam ser ligados à um aparelho de TV. Na página 176 o texto afirma que haveria "aproximadamente 83 jogos" (WOODCOCK, 2020 p. 176), quando claramente o autor se referia aos diferentes gêneros ${ }^{\mathrm{ix}}$ destes.

Além desses problemas da edição, há um outro, mais problemático que pode comprometer a interpretação do texto e do próprio marxismo, nas páginas 179-180, onde há uma citação de Marx e Engels em A ideologia alemã que diz "'O comunismo é para nós um estado de coisas a se estabelecer, um ideal ao qual a realidade terá de se ajustar"” (WOODCOCK, 2020 p. 179), a frase aqui assume um contexto diferente do original, já que se tratava de uma negação desta ideia pois afirma "O comunismo não é para nós um estado de coisas" (MARX \& ENGELS, 2013 p. 38), se faz premente que tal erro seja corrigido nas próximas edições.

Conforme foi apontado nesta resenha, Marx no Fliperama é um livro orientado pela perspectiva da luta de classes, assentado numa visão da totalidade e que é recomendado para todos que desejam compreender o imenso fenômeno que os games têm sido, pelo menos desde a década de 1990, em todas as suas dimensões, desde ao processo de produção até o próprio ato de jogar. Uma análise que confirma a capacidade do método do materialismo histórico de ir além das aparências, relevando as coisas tais quais elas são, superando as ideologias e o senso comum. Trata-se também de um livro para orientar os trabalhadores dessa indústria em todo o mundo sobre seu próprio papel, no mesmo espírito do Manifesto, que dizia: “Trabalhadores de todo o mundo, uni-vos".

Revista RBBA Revista Binacional Brasil Argentina Vol. 10, num. 2, dez/2021, p. 406-413 


\section{REFERÊNCIAS}

MARX, Karl. O Capital: crítica da econômica política: Livro III: O processo global de produção capitalista. São Paulo: Boitempo Editorial, 2017.

WOODCOCK, Jamie. Marx no Fliperama: Videogames e luta de classes. São Paulo, SP: Autonomia Literária, 2020.

\section{NOTAS}

\footnotetext{
${ }^{i}$ Termo em inglês usado para designar jogadores de videogames.

ii Sigla de Non-Playable Character, personagem não jogável, em inglês.

iii "Cyberpunk 2077 has involved months of crunch, despite past promises" Disponível em: https://www.polygon.com/2020/12/4/21575914/cyberpunk-2077-release-crunch-labor-delays-cd-projekt-red acessado em: 15/10/2021.

iv Termo usado para designar os longos períodos de trabalho sem interrupção nos estúdios.

"Nintendo: Animal Crossing delay means avoiding crunch" Disponível em: https://www.gamesindustry.biz/articles/2019-06-12-nintendo-animal-crossing-delay-means-avoiding-crunch acessado em: $15 / 10 / 2021$.

vi "Nintendo's Market Value Drops By $\$ 1$ Billion After Animal Crossing Switch Delay" Disponível em: https://www.nintendolife.com/news/2019/06/nintendos_market_value_drops_by_usd1_billion_after_animal_crossing_s witch_delay acessado em: 15/10/2021.

vii“"Entenda o escândalo na Activision Blizzard” Disponível em: https://observatoriodegames.uol.com.br/colunas/entendao-escandalo-na-activision-blizzard acessado em: 15/10/2021

viii Sigla em inglês para First Person Shooter, Tiro em Primeira Pessoa, em inglês.

${ }^{i x}$ Quer dizer, diferentes tipos de jogo, como os de tiro, RPG, aventura, etc..
} 